\section{BMJ Paediatrics Open}

\title{
Paediatric neuro-oncology rehabilitation in the UK: carer and provider perspectives
}

\author{
Bethan Treadgold (D) , ${ }^{1}$ Colin Kennedy, ${ }^{2}$ Helen Spoudeas, ${ }^{3}$ Elaine Sugden, ${ }^{4}$ \\ David Walker, ${ }^{5}$ Kim Bull (D) ${ }^{2}$
}

To cite: Treadgold B, Kennedy C, Spoudeas $\mathrm{H}$, et al. Paediatric neuro-oncology rehabilitation in the UK: carer and provider perspectives. BMJ Paediatrics Open 2019;3:e000567. doi:10.1136/ bmjpo-2019-000567

- Additional material is published online only. To view please visit the journal online (http://dx.doi.org/10.1136/ bmjpo-2019-000567).

Received 29 August 2019 Revised 23 September 2019 Accepted 23 October 2019

Check for updates

\section{(c) Author(s) (or their} employer(s)) 2019. Re-use permitted under CC BY-NC. No commercial re-use. See rights and permissions. Published by BMJ.

${ }^{1}$ Department of Primary Care and Population Sciences, University of Southampton, Southampton, UK

${ }^{2}$ Clinical and Experimental Sciences, University of Southampton, Southampton, UK ${ }^{3}$ Centre for Paediatric Endocrinology, University College London, London, UK ${ }^{4}$ Oxford, UK

${ }^{5}$ Children's Brain Tumour Research Centre, University of Nottingham, Nottingham, UK

\section{Correspondence to} Dr Colin Kennedy; crk1@ southampton.ac.uk

\section{ABSTRACT}

Objective The provision of rehabilitation services after childhood brain tumour has not been established, despite a recent parliamentary call for urgent action. This service evaluation aimed to determine what specialist paediatric neuro-oncology rehabilitation services were available across the UK at the time of the surveys and whether the needs of patients and their families were being met.

Design Cross-sectional on-line surveys.

Participants Survey 1: neuro-oncologist and nurse specialist members of the Children's Cancer and Leukaemia Group (CCLG) at Children's Principle Treatment Centres (PTCs) in the UK; Survey 2: parents of paediatric neuro-oncology patients belonging to The Brain Tumour Charity (TBTC) Research Involvement Network (RIN).

Results 17 of the $20(85 \%)$ PTCs in the UK and two teenagers and young adult cancer units responded to Survey 1 , and 17 members of TBTC's RIN responded to Survey 2. Access to inpatient and outpatient neurooncology rehabilitation services after treatment for a central nervous system (CNS) tumour varied across regions in the UK. Service users in the RIN identified a need for an established neuro-oncology rehabilitation service for young people, a need for better communication across services and with families, and a need to fill gaps in multidisciplinary teams.

Conclusion The urgent need for specialist paediatric, teenage and young adult neuro-oncology rehabilitation services in the UK is often unmet, particularly for outpatients. Where services are not provided for those children and young people disadvantaged by the diagnosis of a CNS tumour, in clear breach of current guidelines, remedial action needs to be taken to ensure appropriate and equal access.

\section{BACKGROUND}

Central nervous system (CNS) tumours are the most common type of solid tumour to develop in children and young people, and every year around 400 newly diagnosed cases receive care at Children's Principle Treatment Centres (PTCs) in the UK, all of which belong to the UK Children's Cancer and Leukaemia Group (CCLG). The cumulative risk for a young person developing a brain tumour from birth until age 25 is

\section{What is known about the subject?}

- Survivors of childhood central nervous system tumour are at significant risk of adverse 'late effects'; rehabilitation is therefore a key part of the journey to recovery.

- The provision of rehabilitation services after childhood brain tumour has not been specified by healthcare purchasers, despite a recent parliamentary call for urgent action.

- The services currently provided and their perceived ability to meet the needs of affected families have not been assessed.

\section{What this study adds?}

- Highlights an urgent need to establish equal access across the UK to a comprehensive neuro-oncology rehabilitation service for children, young people and their families.

- The first insight into the core needs of young people and their families from neuro-oncology rehabilitation services, barriers to accessing services and gaps in services.

- Recommendations for how to implement such service provisions.

1/980 (information from Public Health England), with brain tumours accounting for $20 \%-25 \%$ of all cancers in the first 25 years of life. This is undoubtedly a significant health risk for young people.

Across Europe, 5-year survival for all CNS tumours has been reported to be $65.4 \%{ }^{1}$ Survivors of childhood CNS tumour are at significant risk of unwanted health-related effects including neurocognitive dysfunction, seizures, sensory and motor deficits, endocrinopathies and psychosocial difficulties. ${ }^{2-5}$ Many of these effects arise or continue after completion of antitumour treatment and are then conventionally referred to as 'late effects'. ${ }^{6-8}$ However, this does not acknowledge that 'brain effects' 
are not necessarily 'late'. Rehabilitation is therefore an important part of the journey to recovery from immediately after the diagnosis of a CNS tumour.

Services for children and young people with cancer and CNS tumours are commissioned by NHS England and the devolved administrations in Wales, Scotland and Northern Ireland. There are 17 Children's PTCs in England and similar centres in Cardiff and Belfast. Scotland has a managed clinical network of four centres. ${ }^{9}$ NHS England also commissions PTCs for Teenagers and Young Adults (TYAs) up to the age of $25 .{ }^{10}$ The need for services to meet the specific needs of children with CNS tumours, including neuro-rehabilitation, was recognised in a 1997 report $^{11}$ and reinforced by The National Institute for Health and Care Excellence (NICE) 2005 guidelines on the commissioning of oncology services for young people in England and Wales. This recognised that, among cancer survivors, those diagnosed with CNS tumours experience the greatest needs due to the effects of the tumour and multimodal therapies. ${ }^{12}$

The 2005 NICE guidance has been reinforced in subsequent published guidelines recommending neurooncology rehabilitation for young people ${ }^{1314}$ and also in the November 2018 report of the All Party Parliamentary Group on Brain Tumours (https://www.braintumourresearch.org/campaigning/inquiry) 2018. ${ }^{15}$ This report detailed the severe long-term consequences of brain tumours for children and young people and recommended that the Recovery Package, which is currently being rolled out across England, (be implemented) by 2020 and made available to all children and young people living with and beyond a brain tumour diagnosis ensuring inclusion of specific services, for example, neuro-rehabilitation.' (ibid.).

In spite of the existence of these guidelines, implementation of their recommendations nationally has not been assessed and there are no specific guidelines dedicated exclusively to rehabilitation of brain tumour survivors. More generally, the provision of a rehabilitation service after childhood brain tumour, including interdisciplinary working between paediatric oncology, paediatric neurology, nursing, therapy, psychology, dietetic, educational and social care providers, has not been specified by healthcare purchasers. This is in contrast to the national commissioning of neurorehabilitation services for children and young people surviving other types of brain injury. Links between those providing neuro-rehabilitation to these two groups of children and young people are often weak and sometimes absent.

This service evaluation therefore used surveys of service providers and service users to determine what specialist paediatric neuro-oncology rehabilitation services were available at the time of the surveys and what future research and changes in provision are required by service users and their families.

\section{METHODS}

\section{Participants}

Neuro-oncologist members of the CCLG and nurse specialists from all 20 PTCs and some TYA PTCs within the UK were sent invitations to participate in Survey 1 (see online supplementary appendix 1). Members of TBTC's Research Involvement Network (RIN), which consists of current and previous CNS tumour patients and their families, were involved in Survey 2 (see online supplementary appendix 2).

\section{DESIGN AND MEASURE}

Both on-line surveys were designed for the purpose of this study with support from members of the CCLG's Neuro-oncology Special Interest Group and a paediatric neuro-rehabilitation nurse specialist at University Hospital Southampton NHS Foundation Trust. The surveys were administered by SurveyMonkey. Survey 1 Neuro-oncology rehabilitation services survey children and young people'included 20 items with a mixture of open-ended and closed questions asking for details about what neuro-oncology rehabilitation services their centre currently provided. All items were accompanied by an optional open response text box for elaboration of the response given. Survey 2 Patients' and Families' Experiences Following Treatment for a CNS tumour in Childhood'consisted of 10 open-ended items and aimed to gather information about the RIN's views of current services and what research into the needs of survivors and changes in provision are required within the UK.

\section{PROCEDURE}

In March 2017, an invitation to participate in Survey 1 was emailed from the CCLG co-ordinating office to members of the CCLG with a special interest in neuro-oncology at all 20 PTCs and some TYA PTCs in the UK. Respondents were asked to complete the survey themselves or pass it to another appropriate neuro-oncologist or specialist nurse in their centre, or complete it jointly, one survey per centre. Fortnightly reminders to complete the survey were sent to centres who had not yet participated. The survey was active for 12 weeks. In July 2017, TBTC's patient involvement and project officer emailed an invitation to TBTC's RIN to complete Survey 2. Fortnightly reminders to complete the survey were sent to members. The survey was active for 8 weeks.

\section{Analysis of surveys' items}

The two surveys were analysed separately. Descriptive statistics were used to report the quantitative data, and the narrative content of the open-ended responses was summarised. 
Table 1 Occupation of respondent by the number of centres, which responded to the service evaluation survey

\begin{tabular}{|c|c|}
\hline $\begin{array}{l}\text { Occupation of centre } \\
\text { respondent }\end{array}$ & Number $(n=19)$ \\
\hline $\begin{array}{l}\text { Paediatric or adult neuro- } \\
\text { oncologist }\end{array}$ & 11 \\
\hline $\begin{array}{l}\text { Lead or specialist nurses in } \\
\text { neuro-oncology }\end{array}$ & 5 \\
\hline Physiotherapist & $\begin{array}{l}3 \text { (1 co-completed with a } \\
\text { neuro-oncologist) }\end{array}$ \\
\hline Occupational therapist & 1 \\
\hline Paediatric psychologist & $\begin{array}{l}1 \text { (co-completed with a } \\
\text { neuro-oncologist) }\end{array}$ \\
\hline
\end{tabular}

\section{PATIENT AND PUBLIC INVOLVEMENT}

Patients and the public were not involved in the design of or recruitment to this study. Health professionals helped to design both surveys, informed by their clinical work with survivors. They also helped with the planning for recruitment. Members of TBTC's RIN completed Survey 2 , which gathered their views of current neuro-oncology rehabilitation services.

\section{RESULTS}

Survey 1: neuro-oncology rehabilitation services offered by Children's PTCs and TYA PTCs treated for CNS tumours Seventeen of $20(85 \%)$ PTCs and two TYA PTCs participated. Three PTCs and an unknown number of TYA PTCs did not respond to the invitation to participate. A response was also received from Dublin but was not included in this report as it is outwith the UK health system. A range of healthcare professionals completed the survey (table 1).

Ninety five per cent of the surveyed centres reported that they had access to an inpatient and outpatient rehabilitation service for young people diagnosed with a CNS tumour (table 2). All types of rehabilitation services were reported by each centre as more available and accessible for inpatients than for outpatients. Physiotherapy and occupational therapy were the most available rehabilitation services for inpatients, and both of these services were reported as being easily accessible to inpatients in most centres. The least available rehabilitation services for inpatients were neuropsychology for cognitive testing and educational support (variable depending on geographical location but most likely provided by hospital education services and outreach by paediatric neuro-oncology nurse specialists). Nevertheless, access to these services was still reported by most centres as being moderately or easily accessible, respectively. Physiotherapy and psychology for emotional and behavioural support were reported to be the most available services for outpatients, although ease of access to these services was reported to be moderate and difficult, respectively. Speech and language therapy was reported as the least available rehabilitation service for outpatients.

Seventeen centres $(89 \%)$ identified a variety of gaps and barriers in their access to neuro-oncology rehabilitation services. The comments provided as free text are grouped together below into five principal domains or themes: neuro-oncology rehabilitation services not being established at their centres, lack of communication about such services, lack of specific types of rehabilitation, barriers specifically to outpatients and absence of

Table 2 Numbers of treatment centres (\%) that confirmed each rehabilitation service to be accessible at their centre for children and young people diagnosed with a CNS tumour, with main level of accessibility to those services for inpatients and for outpatients in 2016

\begin{tabular}{|c|c|c|c|c|}
\hline \multirow[b]{2}{*}{ Rehabilitation } & \multicolumn{2}{|l|}{ Inpatient services } & \multicolumn{2}{|l|}{ Outpatient services } \\
\hline & $\begin{array}{l}\text { Number of centres } \\
\text { able to access, } \\
n=19(\%)\end{array}$ & $\begin{array}{l}\text { Ease of access if } \\
\text { available }\end{array}$ & $\begin{array}{l}\text { Number of centres } \\
\text { able to access, } \\
n=19(\%)\end{array}$ & $\begin{array}{l}\text { Ease of access if } \\
\text { available }\end{array}$ \\
\hline Physiotherapy & $19(100)$ & Easy & $18(95)$ & Moderate \\
\hline Occupational therapy & $19(100)$ & Easy & $16(84)$ & Moderate \\
\hline Speech and language therapy & $18(95)$ & Easy & $13(68)$ & Difficult \\
\hline Neuropsychology for cognitive testing & $16(84)$ & Moderate & $17(89)$ & Difficult \\
\hline $\begin{array}{l}\text { Psychology for emotional and } \\
\text { behavioural support }\end{array}$ & $18(95)$ & Moderate & $18(95)$ & Difficult \\
\hline Endocrinology & $18(95)$ & Easy & $16(84)$ & Moderate \\
\hline Ophthalmology & $17(89)$ & Easy & $17(89)$ & Moderate \\
\hline Audiology & $17(89)$ & Easy & $17(89)$ & Easy \\
\hline Educational support & $16(84)$ & Easy & $14(74)$ & Moderate \\
\hline Other & $5(26)$ & & $3(16)$ & \\
\hline None & $1(5)$ & & $1(5)$ & \\
\hline
\end{tabular}

CNS, central nervous system. 
barriers (as two centres did not report any barriers to neuro-rehabilitation) (table 3 ).

\section{Survey 2: potential needs of patients and families for neuro-} oncology rehabilitation services

Eighteen members of TBTC's RIN responded to Survey 2. Every respondent was a parent or carer of a young person who had been treated for a CNS tumour and their responses related to the care their child had experienced in 14 different PTCs in the UK. There were no responses to the survey from children or young people who had themselves been treated for a CNS tumour.

It is clear from the free text responses of parents that there were strongly held views that the neurorehabilitation of their children with brain tumours had not been met as reported in full in table 4. Seven survey respondents $(39 \%)$ stated that a good level of communication between health professionals and families posttreatment for a CNS tumour was fundamental. Survey respondents reported a need for clear guidance about how the patients and their families can manage at home once discharged from hospital; a need for more detailed information about the different CNS tumour treatments and their consequences; and a need for an established point of contact at which families could obtain advice once discharged from hospital. Fourteen (78\%) survey respondents reported four disciplines within the multidisciplinary team to be the core rehabilitative resources needed after treatment for a CNS tumour: physiotherapy, occupational therapy, speech and language therapy, and clinical psychology for emotional and behavioural support. The first three of these were needs of the patient themselves, whereas the last of these was a need of both the patient and their families.

Five (29\%) survey respondents also recommended changes to the way rehabilitation services are managed and operated. Respondents expressed their need for neuro-oncology rehabilitation services to be more locally available to patients' homes and that the different rehabilitation services need to collaborate better across young peoples' rehabilitative journey following treatment for a CNS tumour. Respondents recognised that more financial investment was needed in neuro-oncology rehabilitation services to improve patients' experiences of them.

\section{DISCUSSION}

This study has provided the first insight into the available paediatric neuro-oncology rehabilitation services in the UK. It identified the core needs that patients and their families have with respect to these services, a range of barriers to accessing services and gaps in services. The lack of an established system for rehabilitation of children and young people in the UK after treatment for a CNS tumour was the barrier most often cited by clinicians (Survey 1) and was also prominent in the responses by service users (Survey 2). Services also appeared to be generally more available for inpatients than for outpatients, while access to types of support service (eg, psychosocial, cognitive) varied across treatment centres, thus creating inequality of access to rehabilitation services. For outpatient services, speech and language therapy was the most difficult to access.

Issues identified in both surveys include disparate resources allocated to neuro-oncology rehabilitation services compared with the resources allocated to antitumour treatments; a lack of outpatient rehabilitation services to support the developing child throughout his/ her growing years; and the need for access to a comprehensive paediatric neuro-rehabilitation service. The fact that these issues emerge from both surveys suggests that the identified barriers and gaps result in a failure to meet the rehabilitation needs of these children and young people and their families. It is also particularly notable that parents wanted services to be provided more locally as outpatients. One interesting discrepancy between the surveys was the identification of limited or absent access to neuro-psychology as a problem by care providers in several centres but not by the parents of brain tumour survivors, whereas the need for clinical psychology support was apparent in responses from both these groups. This may simply reflect lack of awareness among service users of the distinction between these two types of psychological services.

The main strengths of this study were its high response rate, with 17 of 20 PTCs providing information and its inclusion of the perspectives of both care providers and service users. The findings are therefore likely to be reliable and generalisable to paediatric neuro-oncology services across the UK. A limitation of the study was that the responders in the RIN were all parents of brain tumour survivors. The perspective of the survivors themselves was therefore not represented, and the sample of parents who responded to the survey was a group who were motivated to join TBTC's RIN and who were able to receive and respond to an on-line questionnaire. Although the individual responses remain valid, as a group they may not be representative of all children and their parents affected by brain tumours. It is unknown whether there were survivors themselves as members of the RIN at the time of the survey, who could have taken part. As well as this, only two TYA PTCs provided responses to the survey. Additionally, the cross-sectional survey design of the study limits the conclusions that can be drawn from the results. It was not possible to validate the responses from the individual centres, and therefore, the availability of services may have been under-reported or over-reported in some cases. However, the survey was anonymous so there was no incentive to do either. A prospective investigation of provision of services, obtaining feedback from both parents and patients, would validate the results we obtained. A way of achieving this might be to include time to provision of services as an outcome measure at peer review. 


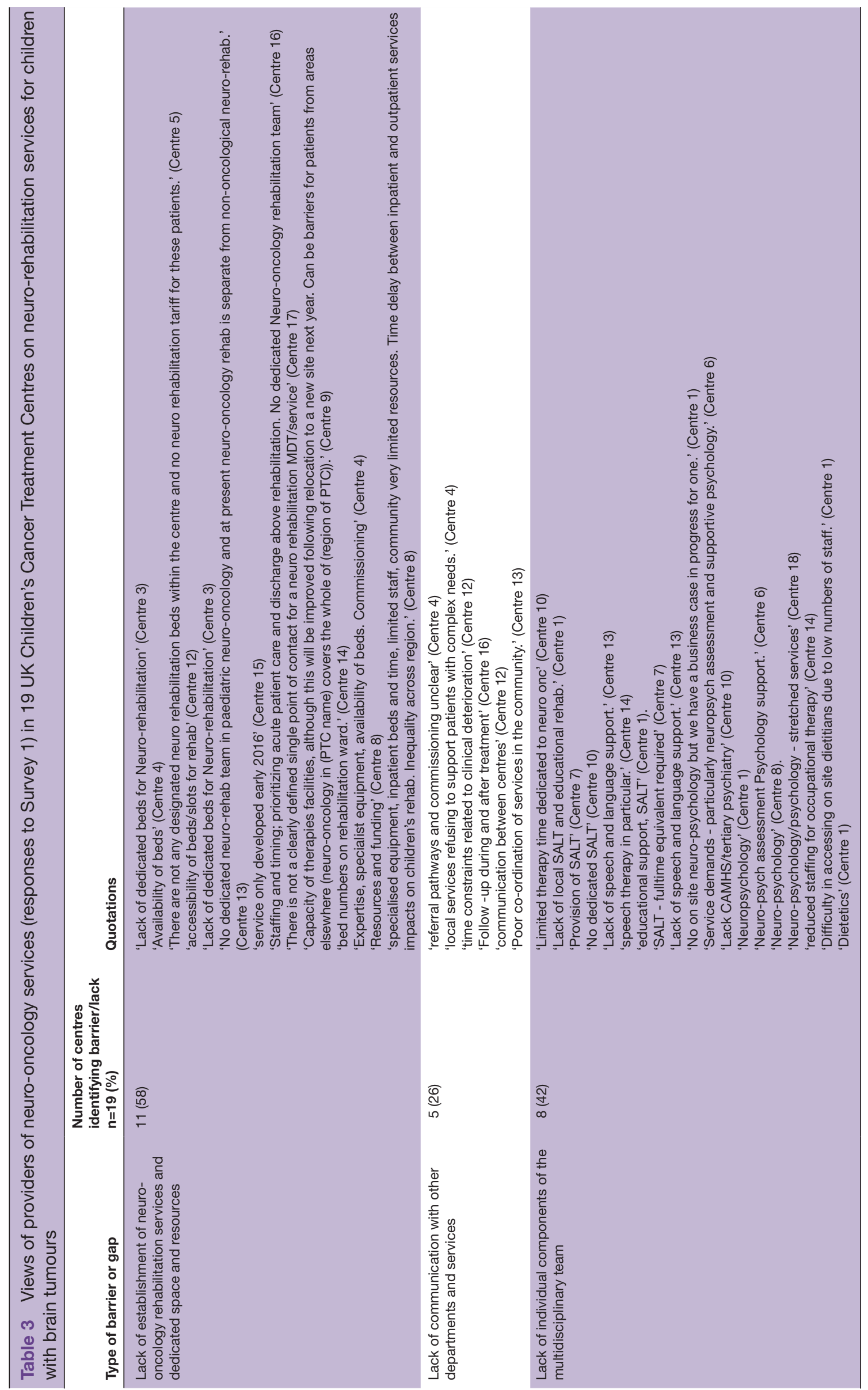

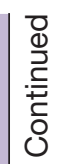




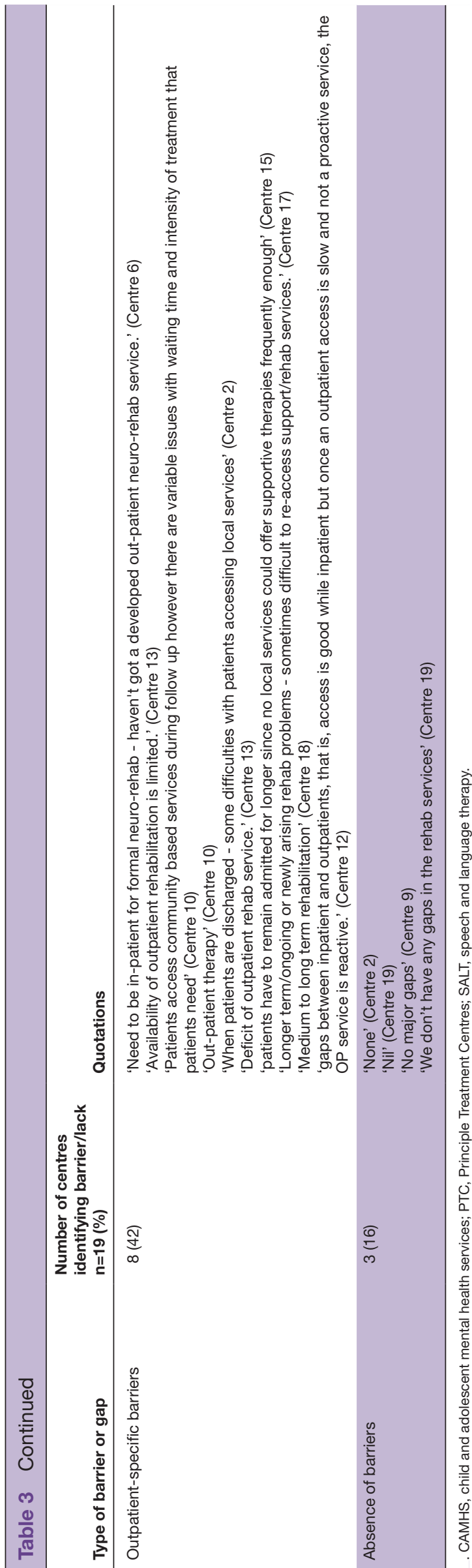

\section{Implications for service provision}

The provision of a paediatric neuro-oncology rehabilitation service has been the standard of care expected since the publication of the 2005 NICE guidelines on the commissioning of oncology services for young people. ${ }^{12}$ These guidelines contain the following recommendations:

- Clear and agreed routes of referral for rehabilitation services across children's cancer networks including the community setting.

- All children with CNS malignancy should have access to a neuro-rehabilitation service during treatment and for years following treatment.

- Cancer networks should liaise with other National Health Service Trusts, local health boards and agencies to establish rehabilitation strategies for psychosocial support and communication with educational services.

- All children with cancer and their families are offered psychological support with clear routes of referral in PTCs and other treatment settings, including during long-term follow-up.

- An appropriate keyworker is assigned to all patients on long-term follow-up.

Similarly, the All Party Parliamentary Group on Brain Tumours 2018 report recommended that 'all children and young people living with and beyond a brain tumour diagnosis' be offered 'specific services, for example neuro-rehabilitation', by $2020 .{ }^{10}$

The deficiencies apparent from these surveys highlight an urgent need to establish equal access across the UK to a comprehensive neuro-oncology rehabilitation service for children and young people who are survivors of CNS tumours, whether inpatients or outpatients. Services that are currently lacking should be put in place to provide access and equality of access to the children and young people who require them.

Neuro-rehabilitation services for children with other types of acquired brain injury have also been historically patchy in the UK but are now commissioned as regional specialised inpatient and outpatient services for acquired neurological injury. A comprehensive paediatric neurorehabilitation service is necessarily interdisciplinary and its elements are specified in the NHS Standard Contract for Paediatric Neurorehabilitation. ${ }^{16}$ Brain tumours are included in the case of need made within that standard contract (ibid. p.2). Its component parts include physio-, occupational, speech and language, and play therapies, clinical and neuro-psychology, dietetics, neurology/ neurorehabilitation, the hospital education service, access to neuropsychiatry and child and adolescent mental health services (CAMHS), and close liaison with local paediatric neuro-disability services. Although likely to be a cost-effective solution where available, the benefits of linking paediatric neuro-rehabilitation following childhood tumours of the CNS with other paediatric neuro-rehabilitation services will depend on the ways in which the various regional and local specialist services 


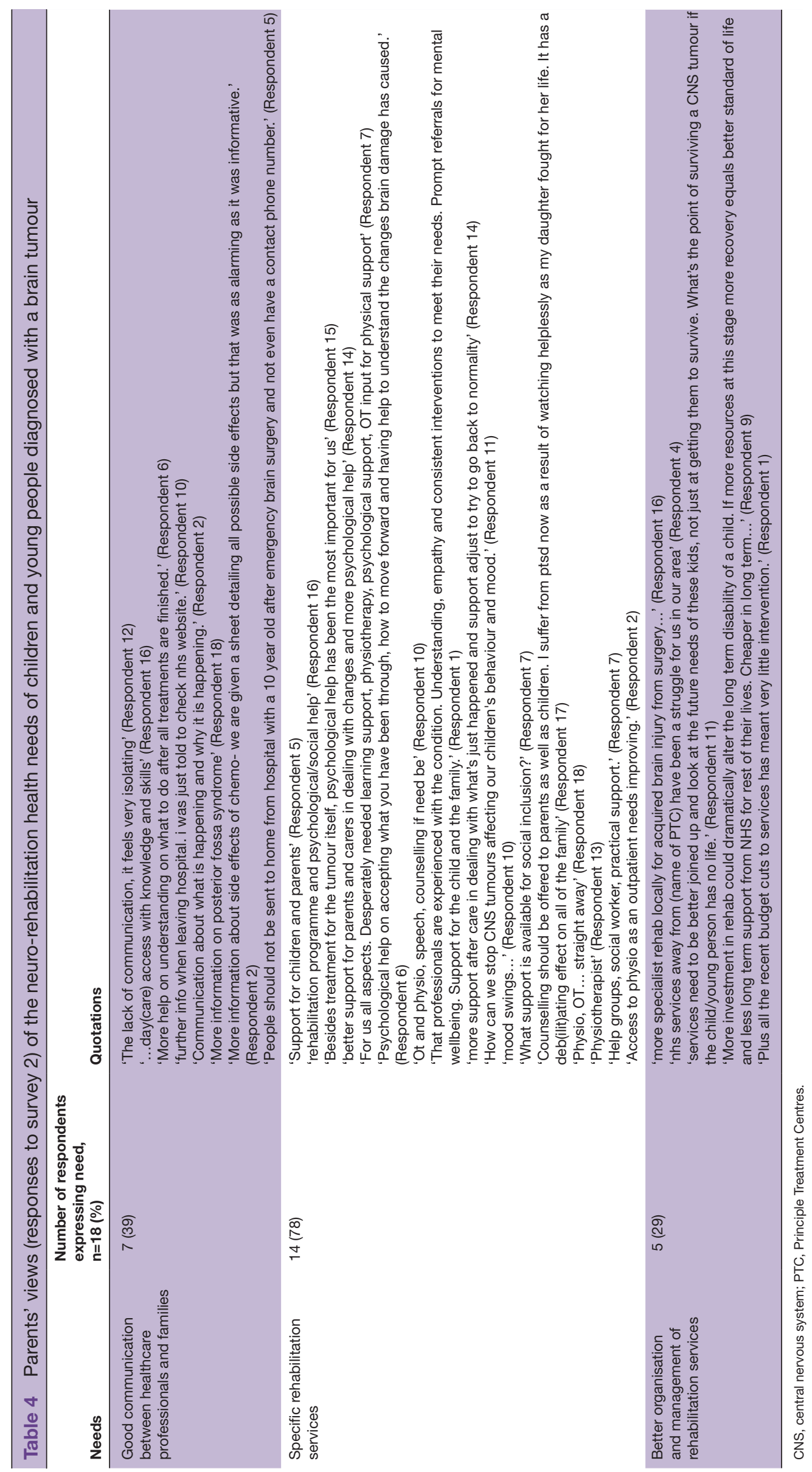


are deployed in each region. The need to consider this possibility applies to all PTCs in the UK.

Acknowledgements We thank Shona Mackie, Nurse Specialist, for her help in the design of the survey; Ashley Gamble, CE0 of CCLG, for distributing Survey 1; The Brain Tumour Charity for engaging their Research Involvement Network with Survey 2; and all the clinicians and parents who took the time to complete the surveys.

Contributors BT contributed to the study design, literature search, data collection, data analysis, data interpretation and writing the manuscript. CK contributed to the original concept of the study, the study design, literature search, data interpretation and writing the manuscript. HS, ES and DW contributed to the original concept of the study, study design, data interpretation and writing the manuscript. KB contributed to the original concept of the study, the study design, literature search, data collection, data analysis, data interpretation and writing the manuscript.

Funding The authors have not declared a specific grant for this research from any funding agency in the public, commercial or not-for-profit sectors.

Competing interests None.

Patient consent for publication Not required.

Ethics approval Survey 1 was approved by the University of Southampton's Faculty of Medicine Ethics Committee (ref: 25374). Ethics approval was not required for patient and public involvement in Survey 2.

Provenance and peer review Not commissioned; externally peer reviewed.

Data availability statement All data relevant to the study are included in the article or uploaded as supplementary information.

Open access This is an open access article distributed in accordance with the Creative Commons Attribution Non Commercial (CC BY-NC 4.0) license, which permits others to distribute, remix, adapt, build upon this work non-commercially, and license their derivative works on different terms, provided the original work is properly cited, appropriate credit is given, any changes made indicated, and the use is non-commercial. See: http://creativecommons.org/licenses/by-nc/4.0/.

ORCID iDs

Bethan Treadgold http://orcid.org/0000-0002-0255-7422

Kim Bull http://orcid.org/0000-0002-5541-4556

\section{REFERENCES}

1 Gatta G, Botta L, Rossi S, et al. Childhood cancer survival in Europe 1999-2007: results of EUROCARE-5--a population-based study. Lancet Oncol 2014;15:35-47.

2 Mulhern RK, Merchant TE, Gajjar A, et al. Late neurocognitive sequelae in survivors of brain tumours in childhood. Lancet Oncol 2004;5:399-408.
3 Boman KK, Hovén E, Anclair M, et al. Health and persistent functional late effects in adult survivors of childhood CNS tumours: a population-based cohort study. Eur J Cancer 2009;45:2552-61.

4 Aukema EJ, Last BF, Schouten-van Meeteren AYN, et al. Explorative study on the aftercare of pediatric brain tumor survivors: a parents' perspective. Support Care Cancer 2011;19:1637-46.

5 Bull K, Kennedy C. Neurocognitive effects of CNS tumors. In: Dulac O, Lassonde M, Sarnat HB, eds. Handbook of clinical neurology. London: Elsevier, 2013: 967-72.

6 Armstrong GT, Liu Q, Yasui Y, et al. Long-Term outcomes among adult survivors of childhood central nervous system malignancies in the childhood cancer Survivor study. J Natl Cancer Inst 2009;101:946-58.

7 Fischer C, Petriccione M, Donzelli M, et al. Improving care in pediatric neuro-oncology patients: an overview of the unique needs of children with brain tumors. J Child Neurol 2016;31:488-505.

8 Children's Cancer and Leukaemia Group. Aftecture. what happens next? Available: https://www.cclg.org.uk/Aftercure/What-happensnext [Accessed 27 Feb 2019].

9 Children's Cancer and Leukaemia Group. In hospital. Available: https://www.cclg.org.uk/In-hospital [Accessed 27 Feb 2019].

10 CLIC Sargent. Children and young people's cancer services: Ambitions for the next 10 years. Available: http://www. youngpeopleshealth.org.uk/wp-content/uploads/2016/06/Childrenand-young-peoples-cancer-services-ambitions-for-the-next-10years-report.pdf [Accessed 27 Feb 2019].

11 Walker D, Hockley A, Taylor R. Guidance for services for children and young people with brain and spinal tumours. Royal College of Paediatrics and Child Health, 1997.

12 National Institute for Health and Clinical Excellence. Guidance on cancer services: improving outcomes in children and young people with cancer. The manual. Available: https://www.nice.org. uk/guidance/csg7/resources/improving-outcomes-in-children-andyoung-people-with-cancer-update-pdf-773378893 [Accessed 27 Feb 2019].

13 NHS Improvement Cancer. Children and young people living with and beyond cancer. designing and implementing pathways to benefit patient aftercare: continuing to build the evidence. Available: https://webarchive.nationalarchives.gov.uk/20130513172502/ http://www.improvement.nhs.uk/LinkClick.aspx?fileticket=Ksxu\% 2bzehcRI\%3d\&tabid=56 [Accessed 27 Feb 2019].

14 Children's Cancer and Leukaemia Group. Aftercure. what to expect in follow up care. Available: https://www.cclg.org.uk/Aftercure/whatto-expect-in-follow-up-care [Accessed $27 \mathrm{Feb} 2019]$.

15 The All-Party Parliamentary Group on Brain Tumours. Brain tumours a cost too much to bear? Available: https://www. braintumourresearch.org/docs/default-source/default-documentlibrary/public-affairs-and-campaigning-documents/18-11-20-braintumours-a-cost-too-much-to-bear_final-report_low-res-singles.pdf? sfvrsn=7fc0ce01 24 [Accessed 27 Feb 2019].

16 NHS England. 2013/14 NHS standard contract for Peadiatric neurorehabilitation. Available: https://www.england.nhs.uk/ wp-content/uploads/2018/09/Paediatric-Neurorehabilitation.pdf [Accessed 27 Feb 2019]. 